American Journal of Agricultural and Biological Sciences 4 (4): 262-265, 2009

ISSN 1557-4989

(C) 2009 Science Publications

\title{
Effect of Delaying Sporulation by Addition of Ammonium Sulphate on the Fermentation of Palm Kernal Cake Based Substrate by Aspergillus niger
}

\author{
${ }^{1}$ K.H. Swe, ${ }^{1,2}$ A.R. Alimon and ${ }^{1,2}$ M. Ramin \\ ${ }^{1}$ Department of Animal Science, Faculty of Agriculture, \\ University Putra Malaysia, 43400 UPM Serdang, Selangor, Malaysia \\ ${ }^{2}$ Institute of Tropical Agriculture, University Putra Malaysia, \\ 43400 UPM Serdang, Selangor, Malaysia
}

\begin{abstract}
Problem statement: Asexual sporulation is a common reproductive mode for a diverse group of fungi and the ultimate limiting factor in fungal biomass production. Approach: Delaying sporulation may increase the biomass in terms of mycelial production and the same time increase production of enzymes. Results: In order to delay the sporulation different levels of ammonium sulphate $(10,12$ and 14\%) were added in culture media as nitrogen source for fungus. It was observed that addition of $14 \%$ ammonium sulphate was the best concentration to add in culture during Solid State Fermentation (SSF) of substrate (Palm Kernel Cake (PKC) + Rice Bran) by Aspergillus niger to delay sporulation. Adding ammonium sulphate also increased the digestibility of fiber in the Fermented Substrate (FS). In addition very low sporulation was observed even after $72 \mathrm{~h}$ of fermentation. The development of spore forming was inhibited or delayed when ammonium sulphate was added compared to the control. Similarly, both NDF and ADF content of FS were decreased in the treatment groups. The higher the ammonium sulphate added to the medium, the lower the NDF and ADF contents of FS although the differences of NDF content were not significant after 3 days or 4 days fermentation. . Conclusion/Recommendations: It was concluded that adding 14\% ammonium sulphate significantly delayed sporulation and increased fungal biomass production in a solid state fermentation system.
\end{abstract}

Key word: Palm kernal cake, sporulation, solid state fermentation, Aspergillus niger

\section{INTRODUCTION}

Sporulation is a well-marked developmental phase in fungi. Spores may be desired end products in some solid-state cultivation process such as starter culture production or plant protection by Trichoderma species, but in other processes, sporulation must be avoided ${ }^{[9]}$. Forage et al. ${ }^{[2]}$ indicated that the time of harvest was critical as prolonged incubation resulted in sporulation, which on a profitable scale is not desirable as the spore may be inhaled by operators. Probably, the most important single factor influencing sporulation of fungi is the concentration of nutrients in the substrates. It is clear that nutrition plays an important part in the production of spores and in determining the time at which sporulation begins. Nutritional requirements for sporulation are almost invariably more specific than for mycelia growth. The nutritional conditions optimal for vegetative growth are not necessarily the best for sporulation, in fact, often inhibit reproduction ${ }^{[4]}$. The mechanism by which high nutrient concentrations inhibit sporulation is not definitely established ${ }^{[1]}$. The concentration of carbohydrate or other source of carbon and a lesser extent of the nitrogenous constituents of the medium are important ${ }^{[4]}$. In contrast, conidiation did not occur in the presence of ammonium ion in spite of glucose exhaustion, although nitrate had no such inhibitory effect $^{[7]}$.

The concentration of $\mathrm{N}$ source in the medium is important for fruiting, i.e., an optimum concentration can be determined under specified conditions. In general, high concentration of $\mathrm{N}$ suppresses sporulation ${ }^{[1]}$. The type of nitrogen compound selected is much important to the fermentologist who is interested not only in the yield, but also in the recovery of the end product. Generally, ammonium salts, nitrates, peptone, amino acids and urea are satisfactory sources of nitrogen for fermentation ${ }^{[5]}$. The objectives of this experiment were to examine the effect of

Corresponding Author: A.R. Alimon, Department of Animal Science, Faculty of Agriculture, University Putra Malaysia, 43400 UPM Serdang, Selangor, Malaysia 
varying levels of ammonium sulphate as a source to inhibit the sporulation of Aspergillus niger.

\section{MATERIALS AND METHODS}

Preliminary studies were carried out in order to evaluate the amount of ammonium sulphate that need to be added in culture media to delay the fermentation. Levels ranging from 1.0-18\% of substrate were tested. Among these concentrations, four different levels ( 0 , 10,12 and 14\%) were selected based on the observations as to the time of fermentation required and the formation of spores.

The fermentation process was conducted using $250 \mathrm{~mL}$ capacity conical flask using the protocols previously described by Swe et al. (2003). Thirty grams of substrate (PKC, 70\% and rice bran $30 \%$ ) were placed in the flasks and a mineral solution was added to obtain a substrate with $50 \%$ moisture content. The mineral solution contained $2 \mathrm{~g} \mathrm{KH}_{2} \mathrm{PO}_{4}, 200 \mathrm{mg} \mathrm{MgSO}$. $7 \mathrm{H}_{2} \mathrm{O}$, $50 \mathrm{mg} \mathrm{FeSO}_{4} 7 \mathrm{H}_{2} \mathrm{O}$ in $1.0 \mathrm{~L}$ of distilled water. Four levels of ammonium sulphate $(0,10,12$ and $14 \%$ of the substrate) were added prior inoculation of the substrate. Spore suspension $\left(2 \times 10^{7}\right.$ spore $\left.\mathrm{mL}^{-1}\right)$ was used as inoculum. Treatments used for this experiment were:

Treatment $1=$ Substrate $+10 \%$ inoculum

Treatment $2=$ Substrate $+10 \%$ inoculum $+10 \%(\mathrm{NH} 4)_{2} \mathrm{SO}_{4}$

Treatment $3=$ Substrate $+10 \%$ inoculums $+12 \%(\mathrm{NH} 4)_{2} \mathrm{SO}_{4}$

Treatment $4=$ Substrate $+10 \%$ inoculums $+14 \%(\mathrm{NH} 4)_{2} \mathrm{SO}_{4}$

The duration of fermentation for each treatment group was 3, 4 and 5 days. Each treatment group was replicated three times.

Chemical analyses: After the respective fermentation times, samples of fermented substrate (FS) were taken and the colony growth of fungus was determined by measuring Colony Forming Unit (CFU). NDF and ADF contents of fermented product were determined by Van Soest ${ }^{[11]}$ method.

Colony forming unit: Potato dextrose agar plates were prepared as nutrient agar for colony. One gram of culture from the flask was taken and placed into sterile glass bottle and diluted with sterilized distilled water from 10 fold to $10^{5}$ times (depends on number of colony). About $100 \mu \mathrm{L}$ of diluted liquid culture was placed on the agar plate and thoroughly mixed by a gentle horizontal rotation of the dish. These plate cultures were kept in an incubator set at $30^{\circ} \mathrm{C}$ for $24 \mathrm{~h}$, after which the presence of colonies throughout the agar was examined. The number of colonies, multiplied by the reciprocal of the dilution, was calculated to determine the number of the organisms.
Statistical analysis: ANOVA was conducted on the data based on a $4 \times 3$ factorial design experiment. Duncan's Multiple Range test ${ }^{[8]}$ was used to compare the differences between the treatment means.

\section{RESULTS}

The number of viable $A$. niger colonies in different treatments for various incubation periods are presented in Table 1 and Fig. 1. The results showed that, in general, there were significant $(p<0.05)$ increases in $\mathrm{CFU}$ with increasing period of incubation. In contrast, increasing the concentration of ammonium sulphate significantly $(\mathrm{p}<0.05)$ decreased the CFU. It was also noted that there were significant differences $(p<0.01)$ in the CFU on day 3 and day 5 fermentation between the treatment groups. Between the fermentation periods, there was no significant difference of CFU on day 4 fermentation between different ammonium sulphate treatments $(\mathrm{p}>0.05)$, although the CFU of culture for $14 \%\left(\mathrm{NH}_{4}\right)_{2} \mathrm{SO}_{4}$ treatment group was the lowest.

Table 2 and Fig. 2 show the effect of addition of ammonium sulphate to the substrate on NDF contents of FS at different fermentation periods. Generally, the higher the ammonium sulphate added in media, the lower the NDF content of FS. However, the difference was not significant. At 5 days fermentation, NDF contents of FS for 12 and $14 \%\left(\mathrm{NH}_{4}\right)_{2} \mathrm{SO}_{4}$ treatments were significantly $(p<0.01)$ lower than those of FS for other treatments.

Table 1: The effect on colony forming unit (CFU) by adding ammonium sulphate during inoculation

\begin{tabular}{|c|c|c|c|}
\hline \multirow{2}{*}{$\begin{array}{l}\text { Incubation } \\
\left(\mathrm{NH}_{4}\right)_{2} \mathrm{SO}_{4}\end{array}$} & \multicolumn{3}{|c|}{ CFU (colony $\mathrm{mL}^{-1}$ ) } \\
\hline & 3 days & 4 days & 5 days \\
\hline $0 \%$ & $11 \times 10^{6} \mathrm{c}$ & $9.5 \times 10^{7}$ & $20.5 \times 10^{7} d$ \\
\hline $10 \%$ & $7.8 \times 10^{6} \mathrm{~b}$ & $6 \times 10^{7}$ & $12.5 \times 10^{7} \mathrm{c}$ \\
\hline $12 \%$ & $7.8 \times 0^{6} \mathrm{~b}$ & $6 \times 10^{7}$ & $7 \times 10^{7} b c$ \\
\hline $14 \%$ & $4.2 \times 10^{6} \mathrm{a}$ & $3.5 \times 10^{7}$ & $4.5 \times 10^{7} \mathrm{a}$ \\
\hline Significance & $\mathrm{p}<0.01$ & NS & $\mathrm{p}<0.01$ \\
\hline
\end{tabular}

Means with different letters in the same column differ significantly $(\mathrm{p}<0.05)$

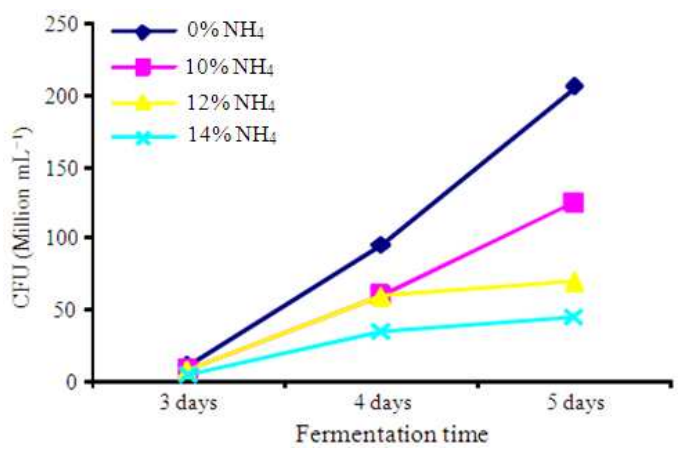

Fig. 1: The effect of ammonium sulphate on CFU of culture 
Table 2: The effect on the percentage of NDF of FS by adding different levels of ammonium sulphate during inoculation

\begin{tabular}{|c|c|c|c|c|c|}
\hline \multirow{2}{*}{$\begin{array}{l}\text { Ammonium } \\
\text { sulphate } \\
(\%)\end{array}$} & \multicolumn{3}{|l|}{$\operatorname{NDF}(\%)$} & \multirow[b]{2}{*}{ Sig. ${ }^{2}$} & \multirow{2}{*}{$\begin{array}{l}\text { Tx } \\
\text { incu }^{3}\end{array}$} \\
\hline & 3 days & 4 days & 5 days & & \\
\hline 0 & $58.51 \pm 0.43^{q}$ & $52.00 \pm 0.74^{\mathrm{p}}$ & $51.16 \pm 0.61^{\mathrm{cp}}$ & $* *$ & NS \\
\hline 10 & $51.98 \pm 0.36^{\mathrm{q}}$ & $48.39 \pm 0.57^{\mathrm{p}}$ & $47.75 \pm 0.85^{\text {bp }}$ & * & NS \\
\hline 12 & $50.68 \pm 0.77^{q}$ & $46.73 \pm 0.55^{\mathrm{p}}$ & $44.94 \pm 0.18^{\text {ap }}$ & * & NS \\
\hline 14 & $50.58 \pm 0.38^{q}$ & $45.26 \pm 0.24^{\mathrm{p}}$ & $45.16 \pm 0.38^{\text {ap }}$ & ** & NS \\
\hline Significance $^{1}$ & NS & NS & $* *$ & & \\
\hline
\end{tabular}

a, b and $c$ : Different superscripts in the same column differ significantly $(\mathrm{p}<0.05) ;{ }^{p}, \mathrm{q}$ and $\mathrm{r}$ : Different superscripts in the same rows differ significantly $(\mathrm{p}<0.05)$; 1 : Statistical differences between different ammonium sulphate level; 2: Statistical differences between different incubation periods; 3 : Interaction between different ammonium sulphate level and incubation periods; NS: Not Significantly different ( $>>0.05)$; *: Significantly different at 5\% level $(\mathrm{p}<0.05)$; **: Significantly different at $1 \%$ level $(\mathrm{p}<0.01)$

Table 3: The effect on ADF content of FS by adding different levels of ammonium sulphate during inoculation

\begin{tabular}{|c|c|c|c|c|c|}
\hline \multirow{2}{*}{$\begin{array}{l}\text { Ammonium } \\
\text { sulphate } \\
(\%)\end{array}$} & \multicolumn{3}{|l|}{$\operatorname{NDF}(\%)$} & \multirow{2}{*}{\multicolumn{2}{|c|}{$\begin{array}{c}\text { Tx } \\
\text { Sig. }{ }^{2} \text { incu }^{3}\end{array}$}} \\
\hline & 3 days & 4 days & 5 days & & \\
\hline & & & & NS & \\
\hline & & & & & \\
\hline & & & & & \\
\hline & & & & & \\
\hline ignificance $^{1}$ & $* *$ & . & & & \\
\hline \multicolumn{6}{|c|}{$\begin{array}{l}\mathrm{a}, \mathrm{b} \text { and } \mathrm{c} \text { : Different superscripts in the same column differ significantly } \\
(\mathrm{p}<0.05) ; \mathrm{p} \text { and } \mathrm{q} \text { : Different superscripts in the same row differ } \\
\text { significantly }(\mathrm{p}<0.05) ; 1 \text { : Statistical differences between different } \\
\text { treatment groups; 2: Statistical differences between different } \\
\text { incubation periods; 3: Interaction between different treatment groups } \\
\text { and incubation periods; NS: Not significantly different }(\mathrm{p}>0.05) ; *: \\
\text { Significantly different at 5\% level ( }<<0.05) ; * * \text { : Significantly } \\
\text { different at } 1 \% \text { level }(\mathrm{p}<0.01)\end{array}$} \\
\hline
\end{tabular}

ADF contents of FS decreased to $44.9 \%$ on day 5 fermentation for Treatment 2 (12\%). NDF contents of FS were significantly $(\mathrm{p}<0.05)$ affected by incubation periods for all treatments and were decreased for longer fermentation period. No significant interaction was observed between different levels of $\mathrm{NH}_{4}$ treatments and incubation periods ( $p>0.05$ ). ADF contents of FS in different treatments for various incubation periods are presented in Table 3 and Fig. 3. ADF values of FS for $\left(\mathrm{NH}_{4}\right)_{2} \mathrm{SO}_{4}$ treatment groups were significantly decreased when compared with those of FS for without $\left(\mathrm{NH}_{4}\right)_{2} \mathrm{SO}_{4}$ treatment $(\mathrm{p}<0.05)$. Those of FS were also significantly $(\mathrm{p}<0.01)$ affected by incubation period for all treatments. Range of ADF values were from 34.9$25.4 \%$ at 3 days fermentation, $33.7-24.4 \%$ at 4 days fermentation and $32.2-23.8 \%$ at 5 days fermentation. ADF content of FS for $14 \%(\mathrm{NH} 4)_{2} \mathrm{SO}_{4}$ treated group at 5 days fermentation period was the lowest among all treatments. There was, however, no significant interaction between different treatments and fermentation periods $(\mathrm{p}>0.05)$.

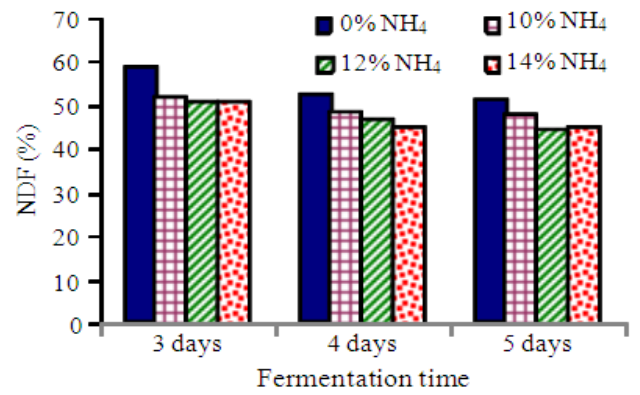

Fig. 2: The effect of ammonium sulphate $14 \%$ on NDF\% of FS

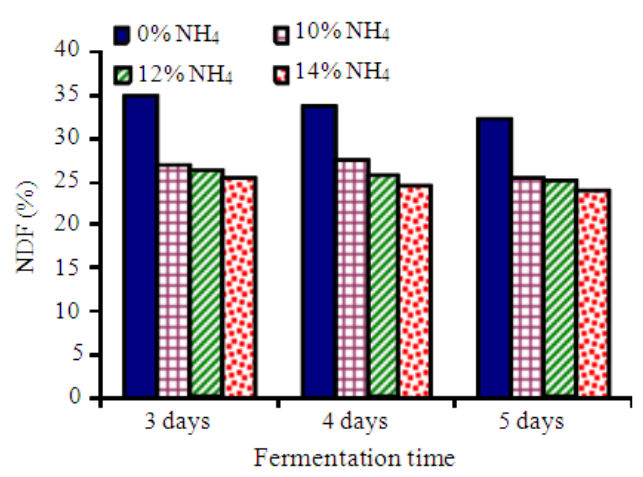

Fig. 3: The effect of ammonium sulphate $14 \%$ on $\mathrm{ADF} \%$ of FS

\section{DISCUSSION}

According to the CFU value of culture, the higher the ammonium sulphate in media, the lower the colony counts per ml. Since, the experimental data shows that the growth of fungus and sporulation of A. Niger were affected by nitrogen level of the culture medium. This finding is in consistent with the statements of Cochrane ${ }^{[1]}$, who noted that the inability of some fungi to grow and sporulate effectively on ammonium salts due in part to the accumulation of acidic ions in the medium. Galbraith and Smith ${ }^{[3]}$ also reported that at the lowest $\mathrm{N}$ concentration normal conidiation occurred and as the higher concentration of $\mathrm{N}$ the development of the conidiophore was delayed or inhibited. Raimbault and Alazard ${ }^{[6]}$ investigated that sporulation was observed after $40 \mathrm{~h}$ in solid-state fermentation of cassava with A. niger. In this study, after $72 \mathrm{~h}$ of fermentation very low sporulation could be observed. Our results show that development of spore forming was inhibited or delayed when compared with the data indicated by above study.

Generally, both NDF and ADF content of FS were decreased for ammonium sulphate treatment groups. 
The higher the ammonium sulphate added to the medium, the lower the NDF and ADF contents of PKC, although the differences of NDF content were not significant for 3 days and 4 days fermentation. The results obtained from this study clearly demonstrate that the ammonium sulphate concentration $14 \%$ of substrate was the optimum level to delay sporulation during fermentation for this experiment as the occurrence of sporulation is a negative option for SSF. The NDF value of FS could be reduced up to $42.5 \%$ and ADF content of FS was decreased to $21.0 \%$ by adding ammonium sulphate in culture.

\section{CONCLUSION}

From this study it can be concluded that $14 \%$ ammonium sulphate was observed as the best concentration to add in culture during Solid State Fermentation (SSF) of substrate (PKC + Rice Bran) by Aspergillus niger to delay sporulation.

\section{ACKNOWLEDGMENT}

The researchers wish to thank Mr. Saparin and Mr. Zakaria for technical assistance during the study.

\section{REFERENCES}

1. Cochrane, V.W., 1958. Physiology of Fungi. John Wiley, London, pp: 524.

2. Forage, A.J. and R.C. Righelato, 1979. Economic Microbiology. Rose, A.H. Academic Press, London, ISBN: 0-12596554-0, pp: 289-313.

3. Galbraith, J.C. and J.E. Smith, 1969. Sporulation of A. niger in submerged liquid culture. J. Gen. Microbiol., 59: 31-45. http://mic.sgmjournals.org/cgi/content/abstract/59/ $1 / 31$
4. Lilian, E.H., 1950. Physiology of Fungi. University of London, Press Ltd., Warwick Square, London, pp: 133-159.

5. Prescott, S.C. and C.G. Dunn, 1959. Industrial Microbiology. 3rd Edn., Mc Graw-Hill Book, Company Inc., New York, pp: 945.

6. Raimbault, M. and D. Alazard, 1980. Culture method to study fungal growth in solid fermentation. Applied Microbiol. Biotechnol., 9: 199-209. DOI: 10.1007/BF00504486

7. Smith, J.E. and J.C. Galbraith, 1971. Biochemical and physiological aspects of differentiation in the fungi. Adv. Microbial Physiol., 5: 45-134. http://www.ncbi.nlm.nih.gov/pubmed/4950260

8. Steel, R.G.D. and J.H. Torrie, 1980. Principles and Procedures of Statistics. A Biochemical Approach. 2nd Edn., McGraw-Hill Publishing Co., New York, ISBN: 0070609268, pp: 633.

9. Swe, K.H., A.R. Alimon, N. Abdullah and D.M. Jaafar, 2003. Protein enrichment of palm kernal cake by solid state fermentation using Aspergillus niger. Malaysian J. Anim. Sci., 8: 59-70.

10. Tengerdy, R.P., 1992. Solid State Cultivation of Lignocellulose. In: Solid Substrate Cultivation, Doelle, H.W., D.A. Mitchell and C.E. Rolz (Eds.). Elsevier Science Publishers Ltd., Crown House, Linton Road, Barking Essex, G. England, ISBN: 1851668799, pp: 269-282.

11. Van Soest, P.J., 1963. Use of detergents in the analysis of fibrous feeds. II A rapid method for the determination of fibre and lignin. J. Assoc. Official Anal. Chem., 46: 829-835. http://www.garfield.library.upenn.edu/classics1979 /A1979HZ28600001.pdf 